\title{
CARACTERIZAÇÃO DA BOVINOCULTURA LEITEIRA DO MUNICÍPIO DE MORRINHOS, ESTADO DE GOIÁS, BRASIL
}

\author{
Wallacy Barbacena Rosa dos Santos ${ }^{1}$, Hozana Alves Chagas ${ }^{2}$, Nariane Coelho de Oliveira ${ }^{3}$, Milena \\ de Lima Vieira ${ }^{3}$, Jeferson Corrêa Ribeiro', Andréia Santos Cezário', Aline Sousa Camargos', Tiago \\ Neves Pereira Valente ${ }^{4}$ \\ 1'Instituto Federal de Educação, Ciência e Tecnologia Goiano - IFGOIANO, Dept. de Zootecnia, Morrinhos, GO. \\ ${ }^{2}$ Engenheira Agrônoma. ${ }^{3}$ Acadêmicas do Curso de Zootecnia do Instituto Federal de Educação, Ciência e Tecnologia \\ Goiano - IFGOIANO, Morrinhos, GO. ${ }^{4}$ Instituto Federal de Educação, Ciência e Tecnologia Goiano - IFGOIANO, Posse, \\ GO. E-mail: wallacy.barbacena@ifgoiano.edu.br
}

\section{RESUMO}

O presente trabalho foi realizado com produtores de pequeno (até $150 \mathrm{l} /$ dia), médio (150 a 300 l/dia) e grande (acima de $300 \mathrm{l} / \mathrm{dia}$ ) porte da produtividade leiteira, tendo o objetivo de caracterizar a produção leiteira do município de Morrinhos - GO. Foram utilizadas 20 variáveis coletadas por meio de informações de questionários aplicados em 40 propriedades leiteiras individuais. Os resultados obtidos demonstraram que a produção média (litros/vaca/ano) foi superior a média do país, com 7,80, 8,66 e 14,55 litros/vaca/dia para os três grupos, respectivamente. 0 aproveitamento de área foi maior para o grupo dos grandes produtores, (19,26 L/ha-1/dia), quando comparado aos 3,14 L/ha-1//dia (pequenos produtores) e 4,74 $\mathrm{L} / \mathrm{ha}^{-1} /$ dia (médios produtores). Quanto a qualidade do leite produzido, somente os pequenos produtores conseguiram atingir a quantidade mínima de CCS exigida pela Instrução Normativa 62 obtendo $381.680 \mathrm{CS} / \mathrm{ml}$. Para a CBT, todos ficaram acima do estipulado, onde os três grupos obtiveram respectivamente $830.860 ; 899.580$ e 318.690 unidades formadoras de colônias $/ \mathrm{ml}$. Os três grupos ficaram com porcentagem de proteína de 3,25\% (pequeno produtor), 3,28\% (médio produtor) 3,25\% (grande produtor) e porcentagem de gordura de 3,51\%, 3,74\%, 3,80\%, respectivamente, obedecendo o exigido. Conclui-se que a pecuária leiteira do município de Morrinhos - GO é formada por produtores especializados e não especializados.

Palavras-chave: características do produtor; manejo de produção; nível tecnológico; qualidade do leite.

\section{CHARACTERIZATION OF DAIRY CATTLE IN THE CITY OF MORRINHOS, STATE OF GOIÁS, BRAZIL}

\section{ABSTRACT}

This work was carried out with small farmer (up to $150 \mathrm{~L} /$ day), medium (150 to $300 \mathrm{~L} /$ day) and large (up to 300 L/day) size of the milk productivity, with the aim of characterizing the dairy production city of Morrinhos - GO. We were used 20 variables collected through of information of questionnaires applied to 40 dairy farms. Results showed that the average production (liters/cow/year) was higher than the national average, with of 7.80, 8.66 and $14.55 \mathrm{~L} / \mathrm{cow} /$ day for the three groups, respectively. Use of area was higher for the group of large producers (19.26 $\mathrm{L} /$ ha/day), compared to $3.14 \mathrm{~L} / \mathrm{ha} /$ day (small producers) and $4.74 \mathrm{~L} / \mathrm{ha} /$ day (medium producers). As regards the quality of milk produced, only small farmers have achieved the minimum amount of CCS required for Normative Instruction 62 of Brazil, obtained $381.680 \mathrm{CCS} / \mathrm{ml}$. For CBT, all were above to stipulated, where the three groups obtained, respectively, 830,860, 899,580 and 318,690 colony-forming $/ \mathrm{ml}$. The three groups were with protein percentage of $3.25 \%$ (small farmer), $3.28 \%$ (medium farmer) and 3.25\% (larger farmer) and fat percentage of 3.51, 3.74\%, and 3.80\% for 3 
groups, respectively. It is concluded that specialized and non-specialized farmers form dairy farming of city of Morrinhos.

Keywords: production management; producer characteristics; quality of milk; technological level.

\section{INTRODUÇÃO}

A produção leiteira tem sido uma excelente fonte de exploração econômica no país. Com o passar dos anos, houve um aumento da população que consome o leite e os seus derivados, porém, tal aumento tem crescimento paralelo à preocupação com a qualidade desses produtos (VIDAL-MARTINS et al., 2005).

A produção nacional de leite em 2015, estimada em 34 bilhões de litros, coloca o Brasil em quarto lugar no ranking mundial dos países produtores. No entanto, apesar de ser um grande produtor, o País ainda importa lácteos para abastecer o mercado interno. De janeiro a julho de 2016 importamos 130,2 mil t de produtos, volume que equivale a 1,1 bilhão de litros de leite. Já as exportações ficaram bem abaixo, somando 25,9 mil t (ZOCCAL, 2016).

Há registro da atividade leiteira em $99 \%$ dos municípios brasileiros, com um rebanho de 23 milhões de vacas ordenhadas. Em toda a cadeia do leite estão envolvidos cerca de 4 milhões de trabalhadores, sendo 11 mil só no transporte do leite da fazenda para a indústria e dos lácteos processados nas indústrias para o mercado (ZOCCAL, 2016).

Para Filho (2008), a produção de leite em uma determinada região, é formada por um conjunto de produtores com perfis distintos, com diferenças em números de rebanho, nível de tecnologia, tratos culturais, necessidade de produção, tipos de alimentação, entre outros. Dessa forma, se torna importante para o produtor ter conhecimento dos custos de produção e se haverá demanda da quantidade produzida para comercialização (HOUSTIOU et al.,2006; GOMES et al., 1989; PRADO et al., 1995; SEBRAE-MG/FAEMG, 1996; MARTINS et al., 2002).

Para os autores Santos e Vilela (2000), no Brasil existem grupos identificados como eficientes na produção leiteira, mais ainda há um público com baixa técnica profissionalizante, o que reflete na variação econômica no setor. Basicamente existem dois grupos de produtores de leite: os especializados e não especializados, onde o segundo grupo não disponibiliza de tecnologias melhoradas, possui rebanho com baixo potencial genético e que geralmente mantém a nutrição a base de pasto, o que gera a instabilidade da produtividade na entressafra.

A qualidade do leite cru é influenciada por vários fatores, os que mais destacam são os zootécnicos, que se refere ao manejo, tipo de alimentação, saúde da glândula mamária, potencial genético, e outros fatores como cuidados com armazenamento do leite logo após a ordenha. Esses cuidados com manejo e higienização contribuirá com os resultados dos parâmetros físicoquímicos, microbiológicos e higiênicos que as indústrias utilizam para determinar a qualidade do leite (SANTOS; FONSECA, 2001).

Ressaltando, a necessidade de haver cuidados com a qualidade da água, pois é imprescindível, a água pode ser uma fonte de contaminação aos animais, se não houver tratamento adequado, por ser utilizada para a lavagem das tetas e de equipamentos como ordenhadeiras e tanques de resfriamento, e utilizada para o consumo dos animais, fazendo com que haja a contaminação por bactérias (COUSIN; BRAMLEY, 1981; SILVA et al., 2016).

A tomada de decisão a respeito do manejo e cuidados de propriedades leiteiras, deve levar em consideração os grupos envolvidos, considerando as variáveis relacionadas à produtividade e o retorno financeiro, assim, as informações necessitam ser precisas e baseadas em dados confiáveis, observando as condições e exigências do mercado local (LOPES et al., 2010). Este trabalho teve como objetivo caracterizar a produção leiteira do município de Morrinhos, Goiás. 


\section{MATERIAL E MÉTODOS}

O presente trabalho foi realizado no município de Morrinhos, no sul do estado de Goiás,

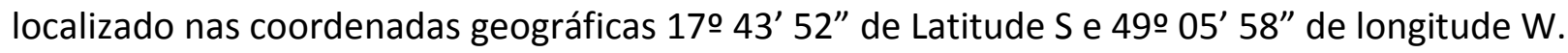

Foram utilizadas informações provenientes de 40 propriedades leiteiras individuais do município. Os dados necessários para a caracterização da pecuária leiteira foram obtidos por meio de entrevistas com os produtores e visitas às propriedades. Os questionários buscaram reunir informações diversas acerca do sistema de produção adotado, sendo aplicado por somente um pesquisador, diminuindo os riscos de incompatibilidade na interpretação dos dados.

As variáveis relacionadas à pesquisa foram: 1 . Área da propriedade; 2 . Número de vacas em lactação; 3. Produção de leite diária; 4. Produção de leite da propriedade; 5 . Produtividade leiteira da propriedade; 6. Valor recebido/litro; 7. Proteína; 8. Gordura; 9. Contagem de células somáticas; 10. Contagem bacteriana total; 11 . Tipo de ordenha; 12 . Teste para avaliação de mastite; 13. Limpeza dos tetos; 14. Resfriamento do leite; 15 . Alimentação no período da seca; 16. Alimentação no período das águas; 17. Água utilizada para consumo animal; 18. Conhecimento das Instruções Normativas 51 e 62; 19. Assistência técnica; 20. Satisfação com a atividade leiteira.

As 40 propriedades foram separadas em três grupos de produtores de leite, sendo formados por doze pequenos produtores (PP), considerando a produção leiteira de até 150L/dia, nove médios produtores (MP), o que obtiveram a produção entre 150 a 300L/dia e dezenove grandes produtores (GP), que produziam acima de 300L/dia.

As entrevistas foram realizadas entre os meses de agosto de 2014 a julho de 2015. A escolha desses períodos teve por finalidade, a obtenção dos dados de produtividade, manejo e qualidade do leite na época da seca e das águas. Os dados obtidos pelo questionário aplicado aos produtores foram comparados aos obtidos pela empresa Complem, para verificação da veracidade das respostas. Informações pertinentes e necessárias à execução desse projeto, como as análises da qualidade do leite, foram obtidas também por meio da empresa Complem, com o intuito de aproximar ainda mais os dados oriundos de amostragem, aos dados reais.

Todas as informações obtidas via questionários foram tabuladas com o uso do programa Microsoft Office Excel 2007. Após a tabulação dos dados, os valores médios foram utilizados para obtenção das análises descritivas pelo programa estatístico SAS UNIVERSIT ${ }^{\circledR}$ (2015).

\section{RESULTADOS E DISCUSSÃO}

Na tabela 1, observa-se que o número de vacas em lactação apresentou valores iguais a 13,5; 33,44 e 58,89 para os PP, MP e GP, respectivamente, com média de produção diária de $90,83,233,33$ e 836,68 litros/dia, concomitantemente. Disponibilizando uma área média de 40,41 $\mathrm{ha}^{-1}$ para PP, 112,05 ha-1 para os PG e 171,66 ha-1 para os MP. Observando o número de vacas por $\mathrm{ha}^{-1}$, há a percepção de que a área utilizada é de $2,99 \mathrm{ha}^{-1} /$ animal para os $\mathrm{PP}$, os MP a área disponível para uma vaca é de $6,98 \mathrm{ha}^{-1} /$ animal e os GP uma média de 1,90 ha-1/animal.

O grupo dos MP apresentaram menor eficiência na utilização das áreas de pastagens, ou seja, mantêm poucos animais em uma área grande. A produção leiteira média em litros/vaca/dia foi de 7,80 para o PP, 8,66 para MP e 14,55 para GP, os três grupos juntos, produziram uma média de 10,34 litros/vaca/dia. Segundo o IBGE (2014), a média de produção de leite nacional é de 4,18 litros/vaca/dia, o que significa que o Município está bem colocado, onde todos os grupos de produtores estão acima da média nacional.

As propriedades obtiveram uma produtividade litros $/ \mathrm{ha}^{-1} / \mathrm{dia}$ de 3,14 para os $\mathrm{PP}, 4,74$ para os MP e 19,26 para os GP. Observa-se que a produtividade por área é maior para o grupo GP, seja por melhores estruturas, melhor aquisição financeira ou conhecimentos técnicos, visto que a raça Girolando é predominante no município para todos os grupos. 
Tabela 1. Valores médios das variáveis de caracterização da propriedade e do rebanho relacionados aos grupos de produtores.

\begin{tabular}{lccc}
\hline & \multicolumn{3}{c}{ Grupos } \\
\cline { 2 - 4 } \multicolumn{1}{c}{ Variável } & Pequeno & Médio & Grande \\
\hline Vacas em lactação (unidades) & 13,5 & 33,44 & 58,89 \\
Produção diária (litros) & 90,83 & 233,33 & 836,68 \\
Área da propriedade (ha-1) & 40,41 & 171,66 & 112,05 \\
Produção média (litros/vaca/dia) & 7,8 & 8,66 & 14,55 \\
Produtividade (litros/ha $/$ /dia) & 3,14 & 4,74 & 19,26 \\
\hline
\end{tabular}

A limpeza dos tetos é realizada apenas por 33, 67 e 58\% pelos três grupos, simultaneamente, segundo a ordem de tamanho. O teste de mastite é aplicado por $42 \%$ dos PP, $67 \%$ dos MP e $84 \%$ dos GP. Nos grupos de PP e MP $67 \%$ deles ainda realizam ordenha manual, alegando não ser compensatório a implantação de ordenha mecânica, sendo somente $33 \%$ que optaram pela implantação da estrutura mecânica, diferente do grupo dos grandes produtores que 100\% utilizam ordenha mecânica, como indicados na tabela 2.

As variáveis médias dos MP permaneceram estáveis para a limpeza dos tetos, realização do teste de mastite e tipo de ordenha, isto justifica que, geralmente o produtor associa esse conjunto de variáveis utilizadas na produção de leite diária e quando se realiza a ordenha manual em regra, não faz um manejo correto de cuidados preventivos com higienização ou testes de mastite.

O resfriamento do leite em todos os grupos é feito em tanque de expansão individual, obedecendo as exigências da Instrução Normativa 62, a qual estabelece que o leite deve ser refrigerado até atingir uma temperatura de 4 C (BRASIL, 2011).

Tabela 2. Valores médios das variáveis de caracterização do manejo de ordenha.

\begin{tabular}{|c|c|c|c|}
\hline \multirow[b]{2}{*}{ Variável } & \multicolumn{3}{|c|}{ Grupos } \\
\hline & Pequeno & Médio & Grande \\
\hline \multicolumn{4}{|l|}{ Limpeza dos tetos (\%) } \\
\hline Sim & 33 & 67 & 58 \\
\hline Não & 67 & 33 & 42 \\
\hline \multicolumn{4}{|l|}{ Teste de mastite (\%) } \\
\hline Sim & 42 & 67 & 84 \\
\hline Não & 58 & 33 & 16 \\
\hline \multicolumn{4}{|l|}{ Tipo de ordenha (\%) } \\
\hline Manual & 67 & 67 & 0 \\
\hline Mecânica & 33 & 33 & 100 \\
\hline \multicolumn{4}{|l|}{ Resfriamento do leite (\%) } \\
\hline Tanque de expansão individual & 100 & 100 & 100 \\
\hline
\end{tabular}

A Instrução Normativa 62 classifica os tratamentos utilizados no leite em três categorias: Leite do tipo A, B e C. Comparando os resultados obtidos na tabela $3 \mathrm{com}$ os da Instrução Normativa 62, observa-se que os teores de proteína e gordura estão em níveis aceitáveis para os três grupos que ficaram com média de proteína de 3,25\% PP, 3,28\% MP 3,25\% GP e média de gordura de 3,51, 3,74 e 3,80\% respectivamente, o que pode indicar que os animais estão recebendo uma nutrição balanceada, já que a alimentação é grande responsável por estes teores.

Tabela 3. Valores médios das variáveis que caracterizam a análise físico-química da qualidade do leite. 


\begin{tabular}{lccc}
\hline \multicolumn{1}{c}{ Variável } & Pequeno & Médio & Grande \\
\hline $\mathrm{CCS}^{1}$ (por ml de leite) & 381.680 & 626.950 & 481.560 \\
$\mathrm{CBT}^{2}$ (UFC/por ml de leite) & 830.860 & 899.580 & 318.690 \\
PROTEÍNA (\%) & 3,25 & 3,28 & 3,25 \\
GORDURA (\%) & 3,51 & 3,74 & 3,80 \\
\hline
\end{tabular}

${ }^{1} \mathrm{CBT}=$ Contagem Bacteriana Total (Milhar)

${ }^{2} \mathrm{CCS}=$ Contagem de Células Somáticas (Milhar)

UFC= Unidade Formadora de Colônias

A contagem de células somáticas (CCS) também é uma importante ferramenta para o controle da qualidade do leite e da saúde da glândula mamária, seja para a detecção de mastite clínica ou subclínica, além de representar um bom indicador das características qualitativas/higiênicas do leite (SANTOS, 2002).

Para a CCS, a Instrução Normativa 62 (IN 62) em vigência determina 400.000 células somáticas/ml de leite (BRASIL, 2011). A observação desses valores na tabela 3, mostra que, os PP conseguiram manter o valor da CCS (Contagem de células somáticas/ml) em um número aceitável, atingindo $381.680 \mathrm{CS} / \mathrm{ml}$, mesmo com a baixa preocupação no manejo de limpeza na ordenha, tal fato provavelmente deve-se a presença do bezerro junto a mãe logo após a ordenha, o que contribui para a não existência de leite residual.

O grupo de MP apesar de realizarem um manejo de limpeza mais eficiente, lavagens dos tetos, realização de pré e pós "dipping", não conseguiram manter o nível de CCS dentro do exigido pela IN 62, apresentando valor médio de $626.950 \mathrm{CS} / \mathrm{ml}$. Já o grupo dos GP que afirmaram serem mais rigorosos com a limpeza, que realizam os testes de mastite e que realizam $100 \%$ de ordenha mecânica, também não foram eficientes em manter o nível da CCS dentro dos padrões estabelecidos pela instrução normativa em vigência, resultando em $481.560 \mathrm{CS} / \mathrm{ml}$.

Esses resultados evidenciam que somente um nível tecnológico mais alto para realizar a ordenha não é suficiente para a melhoria da qualidade do leite, pois, o grupo que utiliza o maior índice de tecnificação não obteve os melhores resultados nas análises. Portanto, para esse parâmetro é importante levar em consideração a higienização da ordenha/ordenhador, do animal, as condições sanitárias do ambiente onde estão as instalações, e principalmente o cuidado com o transporte do leite (CERQUEIRA; SENA 1998).

Para determinar a CBT (Contagem Bacteriana Total/ml) a IN 62 vigente até junho de 2016, exige que os resultados das análises estejam no máximo com 300.000 unidades formadoras de colônias/ml. Os resultados apresentados na tabela 3, revelam que todos os grupos estão fora da realidade exigida pela Normativa, obtendo médias respectivamente de 830.860, 899.580 e 318.690 unidades formadoras de colônias/ml para os três grupos, segundo o tamanho, o que traz uma grande preocupação, pois a Normativa está aprimorando a cada ano, passando a ser mais rigorosa desde julho de 2016. Muitos produtores não apresentam resultados dentro dos padrões estabelecidos simplesmente por desconhecimento sobre o assunto e por não saberem como proceder para produzir leite com qualidade.

Observa-se na tabela 4, a porcentagem de conhecimento sobre as Instruções Normativas 51 e 62, as quais estabelecem parâmetros de qualidade do leite. Os dados demonstram que 33\% dos PP, $44 \%$ dos MP e $79 \%$ dos GP, afirmaram ter conhecimentos sobre as mesmas. A Instrução Normativa № 62 que está atualmente em vigor, estabelece padrões para determinar as qualidades físicas, químicas e microbiológicas, contagem de células somáticas (CCS) e resíduos químicos, como por exemplo, a quantidade de antibióticos encontrados no leite (BRASIL, 2011).

Tabela 4. Valores médios das variáveis de caracterização do conhecimento da Legislação da qualidade do leite, satisfação com a atividade, assistência técnica e retorno financeiro. 


\begin{tabular}{lccc}
\hline \multicolumn{1}{c}{ Variável } & Pequeno & Médio & Grande \\
\hline Conhecimento das Instruções Normativas 51 e 62 (\%) & 33 & 44 & 79 \\
Sim & 67 & 56 & 21 \\
Não & & & \\
Satisfação com a atividade leiteira (\%) & 0 & 0 & 58 \\
Satisfeito & 100 & 100 & 42 \\
Insatisfeito & & & \\
Assistência técnica (\%) & 58 & 44 & 79 \\
Sim & 42 & 56 & 21 \\
Não & 0,89 & 0,92 & 1,00 \\
Valor médio recebido/litro (R\$) & & &
\end{tabular}

Quanto aos valores médios referente a satisfação com a atividade leiteira, 100\% dos PP e MP afirmaram estarem insatisfeitos, enquanto $58 \%$ dos GP apresentaram satisfação. Essa insatisfação é notável pela falta de incentivo do retorno financeiro, devido à instabilidade no valor comercial do leite. A assistência técnica é prestada em $58 \%$ das PP, $44 \%$ das MP e $79 \%$ das GP, observando que a porcentagem de assistência técnica, correspondeu aos conhecimentos das Normativas 51 e 62 para os MP e GP. O valor médio recebido por litro do leite foi $R \$ 0,89, R \$ 0,92$ e $\mathrm{R} \$ 1,00$ para os três grupos, respectivamente.

Segundo a ESALQ/USP, (2015), o preço médio por litro de leite no país em janeiro de 2015 foi de $R \$ 0,84$, considerando uma queda quando comparado com dezembro de 2014 que saiu por $\mathrm{R} \$ 0,89$. De acordo com essa afirmação percebe-se que o valor pago no município está acima da média nacional, o que deve representar um incentivo para o produtor continuar na atividade da pecuária leiteira.

Quanto ao manejo nutricional, verifica-se na tabela 5, onde no período da seca, utiliza-se pasto, concentrado, silagem e sal mineral por $67 \%$ dos PP, $78 \%$ dos MP e $100 \%$ dos GP. Em contrapartida, $33 \%$ dos PP e $22 \%$ dos MP ofertam pasto, concentrado, cana e sal mineral na nutrição dos ruminantes. Para o período das águas, os produtores disponibilizam para a nutrição dos animais pasto, concentrado e sal mineral, na proporção de 67, 56 e 100\% para os grupos, PP, MP e GP, sendo que uma parte dos PP e PM oferece somente pasto e sal mineral, sendo estes 33 e $44 \%$ dos PP e MP.

Segundo Kirchof (2005), a condição de pasto é a nutrição mais barata para os bovinos, mas no momento em que há escassez de matéria verde, torna-se importante a suplementação com outros complementos que forneça ao animal os nutrientes necessários para a sua sobrevivência e produção leiteira.

A água utilizada para a higienização das salas de ordenhas, bem como para equipamentos e utensílios e consumo animal é oriunda de poços artesianos e nascentes para todas as propriedades estudadas.

Para João et al. (2014) é fundamental que o produtor de leite conheça a qualidade da água tanto a utilizada para a ordenha, quanto para o seu próprio consumo, pois, nos estabelecimentos leiteiros a água assume grande importância, visto que, além de servir como bebida para os animais, seu uso também é fundamental em atividades relacionadas à ordenha.

Tabela 5. Valores médios das variáveis de caracterização do manejo nutricional, relacionados aos grupos produtores

\begin{tabular}{cccc}
\hline & & \multicolumn{3}{c}{ Grupos } \\
\cline { 2 - 3 } Variável & Pequeno & Médio & Grande \\
\hline Alimentação no período da seca (\%) & & \\
\hline
\end{tabular}




\begin{tabular}{lccc}
\hline Pasto, concentrado, silo e sal mineral & 67 & 78 & 100 \\
Pasto, concentrado, cana e sal mineral & 33 & 22 & 0 \\
Alimentação no período das águas (\%) & & 56 & 100 \\
$\begin{array}{l}\text { Pasto, concentrado e sal mineral } \\
\text { Pasto e sal mineral }\end{array}$ & 67 & 44 & 0 \\
Água para o consumo animal (\%) & 33 & & \\
Com tratamento & 0 & 0 & 0 \\
Sem tratamento & 100 & 100 & 100 \\
\hline
\end{tabular}

\section{CONCLUSÃO}

A produção leiteira no município é composta por pequenos, médios e grandes produtores, sendo estes, com adoção diferentes níveis de tecnologia. A qualidade microbiológica do leite produzido, assim como a contagem de célula somática ainda necessita de melhorias para o atendimento da legislação vigente.

\section{REFERÊNCIAS}

BRASIL. Ministério da Agricultura, Pecuária e Abastecimento. Instrução Normativa no 62, de 29 de dezembro de 2011. Diário Oficial da República Federativa do Brasil, Brasília, 31 dez. de 2011. Seção 1, p. 6.

CERQUEIRA, M.M.O.P., SENA, M.J. Produção higiênica e fatores determinantes da qualidade do leite. Cienc Vet Trop. 1998;1:115-34.

COUSIN, M. A.; BRAMLEY, A. J. The microbiology of raw milk. In: ROBINSON, R. K. Dairy microbiology. New York: Applied Science, 1981. v. 1, p. 119-163.

EMPRESA BRASILEIRA DE PESQUISA AGROPECUÁRIA - EMBRAPA, 2010. Sistemas de produção de leite para diferentes regiões do Brasil. Disponível em: http://www.cnpgl.embrapa.br/sistemaproducao/. Acessado em: 28/12/2016.

ESCOLA SUPERIOR DE AGRICULTURA "LUIZ DE QUEIROZ" - ESALQ Universidade de São Paulo USP. Análise do mês. Janeiro de 2015.

FILHO, A.B. Tipologia de sistemas de produção baseada nas características do leite. Maringá: (s.n.), 2008. $37 \mathrm{f}$.

GOMES, S.T.; CASTRO, M.C.D.; TAVARES, M.S. Análise da influência da produtividade do rebanho no custo de produção de leite. Coronel Pacheco: CNPGL, 1989. 4 p. Comunicado Técnico.

HOSTIOU, N.; VEIGA, J.B. TOURRAND, J. Dinâmica e evolução de sistemas familiares de produção leiteira em Uruará, frente de colonização da Amazônia brasileira. Revista de Economia e Sociologia Rural, Rio de Janeiro, v.44, n. 2, p.295-311, 2006.

INSTITUTO BRASILEIRO DE GEOGRAFIA. Indicadores IBGE. Estatística da produção pecuária. Dezembro de 2014.

JOÃO, J.H.; ROSA, C.A.D.V.L.; NETO, A.T.; PICININ, L.C.A., FUCK, J.J.; MARIN, G. Qualidade da água utilizada na ordenha de propriedades leiteiras do Meio Oeste Catarinense, Brasil. Revista de Ciências Agroveterinárias, v. 10, n. 1, p. 9-15, 2014. 
KIRCHOF, B. Criação da terneira. 6. ed. Porto Alegre: EMATER/RSASCAR, 2005. 36p.

LOPES, A.D.; OLIVEIRA, M.D.S.; FONSECA, M.I. Características técnicas das propriedades de baixa escala leiteira observadas na área de abrangência do escritório de desenvolvimento rural de Jaboticabal - SP. Revista Ciência em Extensão, v. 6, p. 32-45, 2010.

MARTINS, M.C.; SILVA, V.N.O.; SILVA, J.A.B.; DIOGO, J.M.S.; SILVEIRA, M.A.; FRANCO, G.L. Análise econômica da produção de leite orgânico: um estudo de caso no Distrito Federal. Brasília, DF: [s.n.], 2002. CD-ROM.

PRADO, E.; CRUZ, F.E.; VIANNA, F.C.; TORRES, A.M.; REIS, D.L. Avaliação de desempenho técnico econômico de explorações leiteiras em Divinópolis $M G$, segundo a forma de produção. Arquivo Brasileiro de Medicina Veterinária e Zootecnia, Belo Horizonte, v. 47, n. 3, p. 361-372, 1995.

SANTOS, G.T.; VILELA, D. Produção leiteira - analisando o passado, entendendo o presente e planejando o futuro. In: REUNIÃO ANUAL DA SOCIEDADE BRASILEIRA DE ZOOTECNIA, 37., 2000, Viçosa. Anais..., 2000, Viçosa: Sociedade Brasileira de Zootecnia, 2000. P.231-266.

SANTOS, M. V.; FONSECA, L. F. L. Importância e efeito de bactérias psicrotróficas sobre a qualidade do leite. Revista Higiene Alimentar, São Paulo, v. 15, n. 82, p. 13-19, 2001.

SANTOS, M.V. Efeito da mastite sobre a qualidade do leite e derivados lácteos. In: Anais do 2o Congresso Panamericano de Qualidade do Leite e Controle de Mastite; 2002. Ribeirão Preto. Ribeirão Preto: Instituto Fernando Costa; p.179-88.

SAS - STATISTIC ANALYSIS SYSTEM. 2003. User's Guide. SAS Institute In., Cary, NC, USA. 2015.

SEBRAE-MG/FAEMG. Diagnóstico da pecuária leiteira do estado de Minas Gerais. Belo Horizonte, 1996. $102 \mathrm{p}$.

SILVA, L.P.; BUENO, C P.; COELHO, K.O.; PASSOS, A.A.; NEVES, R.B.S.; SANTOS, A.P.P. Qualidade do leite em diferentes tipos de sistemas de ordenhas. Revista de Educação Continuada em Medicina Veterinária e Zootecnia, v. 14, n. 3, p. 60-60, 2016.

VIDAL-MARTINS, A.M.C.; SALOTTI, B.M.; ROSSI JÚNIOR, O.D.; PENNA, A.L.B. Evolução do índice proteolítico e do comportamento reológico durante a vida de prateleira de leite UAT/UHT. Ciências e Tecnologia de Alimentos. v. 4, n. 24, p. 698-704, 2005. https://doi.org/10.1590/S0101$\underline{20612005000400012}$

ZOCCAL, Rosângela. Alguns números do leite. 2016. Disponível em: http://www.baldebranco.com.br/alguns-numeros-do-leite/. Acessado em: 09 abril de 2017. 